\title{
Biomedical Application of Carbon Nanotubes for Proteins Extraction and Seperation
}

\author{
Hartmut Schlüter ${ }^{\mathrm{a}}$ and Mohammadreza Saboktakin ${ }^{\mathrm{b},{ }^{*}}$ \\ ${ }^{a}$ University Medical Centre Hamburg-Eppendorf, Hamburg, Germany \\ ${ }^{b}$ Nanostructured Materials Synthesis Lab., NanoBMat Company, GmbH, Hamburg, Germany
}

\begin{abstract}
Measurement science and technology continue to play vital roles in biomedical research and in routine healthcare. Over recent decades there has been a steady evolution of sensors for biomedical measurement aimed at clinical care in hospitals, fundamental biomedical research in the laboratory, or even self-care in the home. The measurements of interest are diverse, ranging from pressure, force, flow and displacement to electrical field/charge, magnetic flux, and molecular species, such as gases, ions, proteins, bacteria, viruses, and DNA. In this review, we have studied several biomedical applications of nanotubes and nanowires for proteins measurements in cells. Also, These materials have a wide application as protein carriers and transporters. The wide applications of multi-walled carbon nanotubes (MWCNT) on the serious concerns about their safety on human health and environment have been studied.
\end{abstract}

Keywords: Nanotubes, Proteins, Extraction, Seperation, biomedical application.

\section{INTRODUCTION}

Graphene, which is a 2-dimensional one-atom thick carbon layer, and its oxidized derivate, graphene-oxide (GO), benefit from large surface area which can be further functionalized with biomolecules for various applications [13]. Both covalent and noncovalent binding have been used to attach proteins, enzymes, peptides, bacteria, cells, and nucleic acids to graphenes and GOs, for various applications including fluorescence- or electrochemical-based sensors, labeling and imaging, therapy and targeted delivery, and energy storage. CNTs are graphene sheet structures rolled up in the shape of a cylinder which can have an open end or a closed end depending on the synthetic procedure. At present it is clear that the best methods for CNTs synthesis are still chemical vapor deposition (CVD), arc discharge and laser vaporization or laser ablation, with different variants/improvements (especially in catalyst preparation and new carbon sources). However, explanation for the growth mechanism of CNTs is still under a fair amount of controversy. CNTs show very interesting properties that arise from one key feature: the combination of small size and immense surface area. Some of the most relevant properties are their outstanding tensile strength, high thermal conductivity and stability, high resilience, semiconducting and/or conducting electrical properties, etc. Since carbon nanotubes (CNTs) were discovered by lijima in 1991

*Address correspondence to this author at the Nanostructured Materials Synthesis Lab., NanoBMat Company, GmbH, Hamburg, Germany;

E-mail: Saboktakin123@gmail.com
[1], they have become the subject of many studies because of their unique electrical, optical, thermal, and mechanical properties [2-6]. Ever since the discovery of the fullerene, the family of carbon nanostructures has been steadily expanded. Included in this family are single-walled and multi-walled carbon nanotubes (SWNTs and MWNTs), carbon onions and cones and, most recently, SWNHs. These SWNHs with about 40 $50 \mathrm{~nm}$ in tubule length and about 2-3 nm in diameter are derived from SWNTs and ended by a five-pentagon conical cap with a cone opening angle of $\sim 20^{\circ}$. Moreover, thousands of SWNHs associate with each other to form the 'dahlia-like' and 'bud-like' structured aggregates which have an average diameter of about 80-100 nm. The former consists of tubules and graphene sheets protruding from its surface like petals of a dahlia, while the latter is composed of tubules developing inside the particle itself. Their unique structures with high surface area and microporosity make SWNHs become a promising material for gas adsorption, biosensing, drug delivery, gas storage and catalyst support for fuel cell. Single-walled carbon nanohorns are an example of the family of Carbon nanocones. CNTs can be visualized as a sheet of carbon atoms rolled up into a tube with a diameter of around tens of nanometers. There are two main types of CNTs, an be single-walled (SWCNTs) and multiwalled carbon nanotubes (MWCNTs), the latter being formed by several concentric layers of rolled graphite (Figure 1).

In particular, SWCNTs are characterized by a high aspect ratio. In the last decade, CNTs are intensively explored for in vitro and in vivo delivery of therapeutics, 

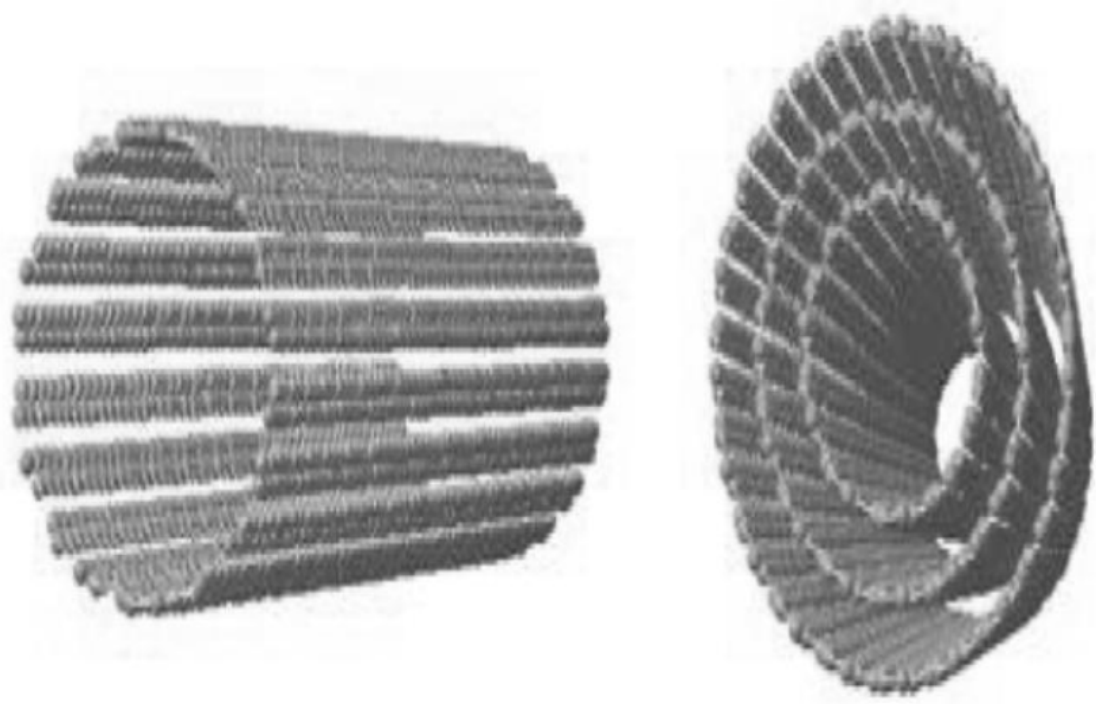

Figure 1: Schematics of SWCNTs and MWCNTs.

which was inspired by an important finding that CNTs can penetrate cells by themselves without apparent cytotoxic effect to the cells [7-9]. The high aspect ratio makes CNTs outstanding from other types of round nanoparticles that the needle-like CNTs allow loading large quantities of payloads along the longitude of tubes without affecting their cell penetration capability. With the adequate loading capacity, the CNTs can carry multifunctional therapeutics, including drugs, genes and targeting molecules, into one to exert multi valence effects. In the other side, owing to the ultrahigh surface area along with the strong mechanical properties and electrically conductive nature, CNTs are excellent material for nano-scaffold and three dimensional nanocomposites. In recent year, CNT based devices have been successfully utilized in tissue engineering and stem cell based therapeutic applications, including myocardial therapy, bone formation, muscle and neuronal regeneration. Furthermore, owing to the distinct optical properties of CNTs such as high absorption in the near-infrared(NIR) range, photoluminescence, and strong Raman shift [10], CNTs are excellent agents for biology detection and imaging. Combined with high surface area of CNTs for attaching molecular recognition molecules, CNTbased, targeted nano-devices have been developed for selective imaging and sensing. There are many areas where CNTs are extremely useful. The Emerging field of nanomedicine has been propelled by the growth and gradual overlap of disciplines such as nanotechnology, biochemistry, pharmacology, and medicine, all of which are themselves highly interdisciplinary. The new field of nanomedicine integrates advanced nanomaterials such as nanowire(NW) arrays with biomolecules, cells, and eventually organisms, in order to develop novel platforms for application such as biosensing, drug screening, and drug delivery. A biosensor is in general an analytical device that responds to biological detection of proteins in the form of electrical signals. It can also be defined as a device in which the response of some chemical biomatrix such as antibodies, enzymes etc. is modified into an electrical signal depending on the concentration of the analyte used. Typically, a biosensor is comprised of a transducer part and a sensing part. The detector part is the one that detects the target cells in the body and the transducer collects the information from the detector and transmits a signal to the output system. The detector part is usually a protein or an enzyme that captures the target cells, while the major part of the sensor is the transducer which changes the characteristics of the whole sensor and allows researchers to develop an effective biosensor so that it can be implanted into a human body. The structure of the transducer part is the main factor that will decide the number of available protein binding sites. one dimensional nanostructures such as nanowires, nanotubes and nanobelts have attracted a great attention in the construction of biosensors due to their unique properties and potential to be fabricated as sensors. With a large surface/volume ratio and a Debye length comparable to the nanostructure radius, the electronic properties of these nanostructures are strongly influenced by surface processes, giving rise to superior sensitivity than their thin film counterparts. In comparison with 2-D films, where the charges are accumulated on the surface, the charge accumulation in 1-D nanostructures occurs in the bulk of the material, which ensures good electrical properties during detection. The 1-D nanostructures are most commonly fabricated by a bottom-up 
approach using synthesis processes. A bottom-up approach is nothing but a chemical reaction that is done using particular reactants under specific conditions. It basically requires a catalyst, a vapor phase reactant (nanostructure material) and a thermal environment to effectively synthesize the nanomaterials. These 1-D nanostructures are chosen particularly due to their high response to external stimulus that can be used for real time monitoring applications. In biochemistry, developments in genomics and proteomics have helped elucidate the molecular basis of many diseases. They have generated knowledge about disease biomarkers, with potential for personalized medicine in diagnostics, in which fine therapies (drug type, dose) can be adapted to each patient, reducing side effects and improving drug efficiency. Drug discovery has also benefited from these developments with the design of new drugs and the development of high through put screening (HTS) strategies for new molecules. Combined with drug delivery strategies based on novel nanomaterials, with better biocompatibility and target specificity, nanomedicine opens the way to a myriad of potential new therapies [11]. PEGylated GO nanoparticles functionalized with transferrin proteins were used to target gastric cancer cells (AGS) which overregulate transferrin receptors. The transferrin-GOx conjugates were used as optical probes for the targeted malignant cells using their two photon photoluminescence, as well as therapeutic agents for photo thermal therapy, causing cell damage under high power laser irradiation. In addition, bovine serum albumin (BSA) reduced GO nanoparticles were intravenously injected into the tail of mice bearing MCF-7 breast cancer tumor, whose cells underwent thermal induced necrosis following laser irradiation. Targeted drug delivery was also demonstrated in vivo using oxidized SWCNT functionalized with epidermal growth factor (EGF) and an anticancer drug, cisplatin. Following the injection of the EGF-SWCNT conjugated into mice with head and neck squamous carcinoma tumors, the nanoparticles targeted the EGF receptors overexpressed on the tumor cells, resulting in slower tumor growth. Based on these developments, there are three main impact areas foreseen for nanomedicine: (1) high-quality and fast diagnosis of diseases, with the development of biosensors, (2) drug discovery, with the development of fast and cheap screening strategies of potential new drugs, and (3) drug delivery with targeted delivery and translocation of active therapeutic reagents. Neuroscience raises additional challenges that can also benefit from the development of novel nanotechnology-based platforms. These challenges stem in particular from the regulation of the brain microenvironment through the blood-brain barrier and the organization of neurons and their specific response to a panel of neurotransmitters. Recently, a couple of laboratories [12] reported on an alternative method of interfacing NWs and cells that holds promise of simpler maneuvering and additional applications. Instead of working with solutions of NWs, suspensions of living cells are added to an array of vertically aligned NWs that are fixed to a surface. Like CNTs, the NW arrays present a major potential in nanomedicine, which possible applications for drug delivery and discovery. In addition, these arrays could provide a huge potential for diagnostics in living cells. Proteomics is the study of the proteome, the protein complement of the genome. The terms "proteomics" and "proteome" were coined by Marc Wilkins and colleagues in the early 1990s and mirror the terms "genomics" and "genome," which describe the entire collection of genes in an organism. These "-omics" terms symbolize a redefinition of how we think about biology and the workings of living systems. Until the mid-1990s, biochemists, molecular biologists, and cell biologists studied individual genes and proteins or small clusters of related components of specific biochemical pathways. The techniques then available-Northern blots (for gene expression) and Western blots (for protein levels)-made charting the status of more than a handful of genes or proteins a formidable analytical task. Three developments changed the biological landscape and formed the foundation of the new biology. The first was the growth of gene, expressed sequence tag (EST), and proteinsequence databases during the 1990s. These resources became ever more useful as partial catalogs of expressed genes in many organisms. The genomesequencing projects of the late 1990s yielded complete genomic sequences of bacteria, yeast, nematodes, and drosophila and culminated recently in the complete sequence of the human genome. Sequences of plant genomes and those of other widely studied animals also are recently completed or are approaching completion. These genome-sequence databases are the catalogs from which much of our understanding of living systems eventually will be extracted. The second key development is the introduction of user-friendly, browser-based bioinformatics tools to extract information from these databases. It is now possible to search entire genomes for specific nucleic acid or protein sequences in seconds. Such database search tools are integrated with other tools and databases to predict the functions of the protein products based on the occurrence of specific functional domains or motifs. This array of free web-based tools now enables the 
biologist to probe structures and functions of genes and gene products and to explore a great deal of interesting biochemistry right from a desktop computer. The third key development is the oligonucleotide microarray. The array contains a series of gene-specific oligonucleotides or cDNA sequences on a slide or a chip. By applying a mixture of fluorescently labeled DNAs from a sample of interest to the array, one can probe the expression of thousands of genes at once. One array can replace thousands of Northern-blot analyses and can be done in the time it would take to do one Northern. Moreover, with two-color fluorescent probe labeling, expression of genes in two different samples can be compared directly on one slide or chip. From this single array, one can assess the expression of all genes in the yeast genome. Such pictures vividly confront us with the greatest challenge of the new biology. We can see the whole system, but the information contained in these thousands of data points is beyond our ability to interpret intuitively. New clustering algorithms, self-organizing maps, and similar tools represent the latest approaches to rendering the data in ways that biologists can comprehend. The most important thing about arrays is that they have challenged biologists to think big. A cell has thousands or tens of thousands of genes that may be expressed in varying combinations. The life and death of cells is dictated by the expression of these genes and the activities of their protein products. Each protein, whether a trans membrane receptor, a transcription factor, a protein kinase, or a chaperone, expresses a function that assumes significance only all the other functions and activities also being expressed in the same cell. Thus, biologists are now struggling to think big, to understand systems rather than just components, and to make sense of complexity. Biomimetic refers to human-made processes, substances, devices, or systems that imitate nature. The art and science of designing and building biomimetic apparatus is also known as biomimicry because they mimic biological systems. The field is of special interest to researchers in nanotechnology, robotics, artificial intelligence (Al), the medical industry, and the military. Some biomimetic processes have been in use for years. An example is the artificial synthesis of certain vitamins and antibiotics. More recently, biomimetics have been suggested as applicable in the design of machine vision systems, machine hearing systems, signal amplifiers, navigational systems, and data converters. A neural network is a biomimetic system that works by making associations and educated guesses, and that can learn from its own mistakes; an android is a humanoid robot designed to have the same basic form and kinetic abilities as a human. Here's how biomimicry is applied to enable an electronic nose:

An electric nose detects the chemical components of an odor and performs analysis to identify it based on that information. Every odor is made up of molecules and each molecule is a particular size and shape, which corresponds to a similarly-sized and shaped receptor in the human nose. When specific receptors in a human nose receive their matching molecules, they send signals to the brain, which identifies the smell associated with those particular molecules. Electronic noses based on the biological model work similarly, substituting sensors for receptors and transmitting the signal to a software program for processing, rather than to the brain. Other possible applications of biomimetics include nanorobot antibodies that seek and destroy disease-causing bacteria, artificial organs, artificial arms, legs, hands, and feet, and various electronic devices. One of the more intriguing ideas is the socalled biochip, a microprocessor that grows from a starter crystal in much the same way that a seed grows into a tree, or a fertilized egg grows into an embryo.

\section{DISCUSSION}

\section{Types of Nanotubes}

A Carbon Nanotube is a tube-shaped material, made of carbon, having a diameter measuring on the nanometer scale. The graphite layer appear appears somewhat like a rolled-up chicken wire with a continuous un broken hexagonal mesh and carbon molecules at the apexes of the hexagons known as graphene. Carbon nanotubes have many structures, differing in length, thickness, and in the type of helicity and number of layers. Although they are formed from essentially the same graphite sheet, their electrical characteristics differ depending on these variations, acting either as metals or as semiconductors. Elemental carbon in the $\mathrm{sp}^{2}$ hybridization can form a variety of amazing structures. A part from the wellknown graphite, carbon can build closed and open cages with honeycomb atomic arrangement. The first such structure to be discovered was the $\mathrm{C} 60$ molecule by Kroto et al. 1985 [13,14]. Although various carbon cages were studied, it was only in 1991, when lijima observed for the first time tubular carbon structures [15]. The Nanotubes consisted of up to several tens of graphitic shells (so called multi-walled carbon nanotubes (MWNT)) with adjacent separation of 0.34 $\mathrm{nm}$, diameters of $1 \mathrm{~nm}$ and high length/diameter ratio [16]. As a group, Carbon nanotubes typically have 
diameter ranging from $<1 \mathrm{~nm}$ up to $50 \mathrm{~nm}$. Their lengths are typically several microns, but recent advancements have made the nanotubes much longer, and measured in centimeters. A grapheme sheet can be rolled more than one way, producing different types of carbon nanotubes [17] and thus carbon nanotubes can be categorized by their structures:

\section{Single-Wall Nanotubes (SWNT)}

Most single-walled nanotubes (SWNT) have a diameter of close to 1 nanometer, with a tube length that van be many millions of times longer. The structure of a SWNT can be conceptualized by wrapping a oneatom-thick layer of graphite called grapheme into a seamless cylinder. The way the grapheme sheet is wrapped is represented by a pair of indices $(n, m)$ called the chiral vector. The integer's $n$ and $m$ denote the number of unit vectors along two directions in the honeycomb crystal lattice of graphene.

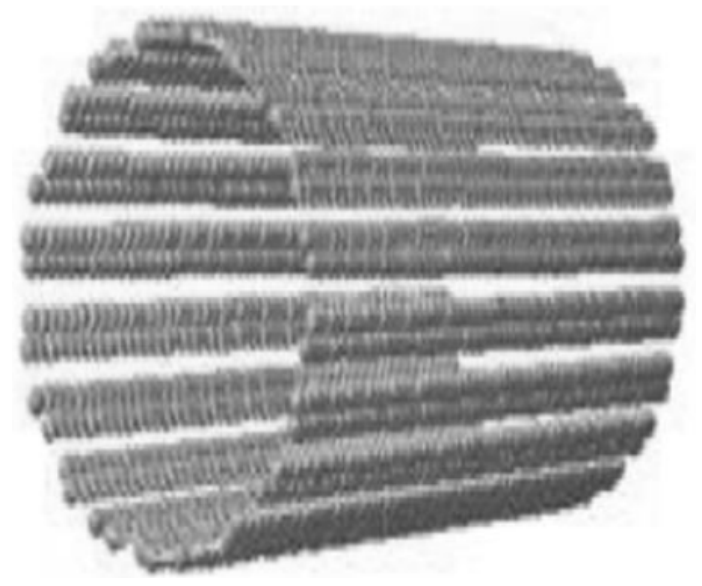

Figure 2: Single walled Nanotubes.

\section{Multiple Walled Carbon Nanotubes}

There are two models which can be used to describe the structures of multi-walled nanotubes. In the Russian Doll model, sheets of graphite are arranged in concentric cylinders, e.g. a single-walled nanotube (SWNT) within a larger single-walled nanotube. In the Parchment model, a single sheet of grapheme is rolled in around itself, resembling a scroll of parchment or rolled newspaper. The interlayer distance in luti-walled nanotubes is close to the distance between grapheme layers in grapheme, approximately $3.3 \AA(330 \mathrm{pm})$. The special place of double-walled carbon nanotubes (DWNT) must be emphasized here because their morphology and properties are similar to SWNT but their resistance to chemicals is significantly improved [18].

\section{Nanororus}

A nanotorus is theoretically described as carbon nano tube bent into a torus (doughnut shape). Nanotori are predicted to have many unique properties, such as magnetic moments 1000 times larger than previously expected for certain specific radii. Properties such as magnetic moment, thermal stability etc. varies widely depending on radius of the torus and radius of the tube. Nano-torus particles are promising in nano-photonics applications [19].

\section{Nanobuds}

Carbon Nanobuds are a newly created material combining two previously discovered allotropes of carbon; carbon nanotubes and fullerenes. In this new material fullerene-like "buds" are covalently bonded to the outer sidewalls of the underlying carbon nanotube. This hybrid material has useful properties of both fullerenes and carbon nanotubes. In particular, they have been found to be exceptionally good field emitters. In composite materials, the attached fullerene molecules may function as molecular anchors preventing slipping of the nanotubes, thus improving the composite's mechanical properties [20].

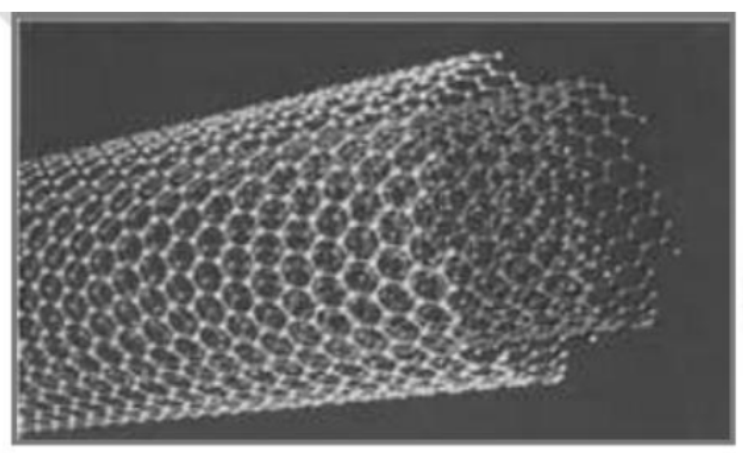

(a)

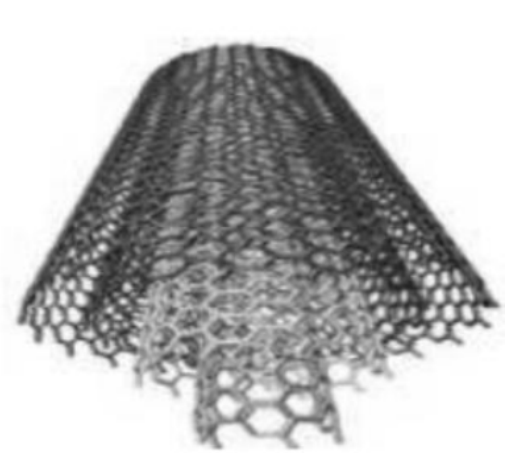

(b)

Figure 3: (a) Double-wall Nanotubes (DWNT), (b) Multi-walled Nanotubes. 


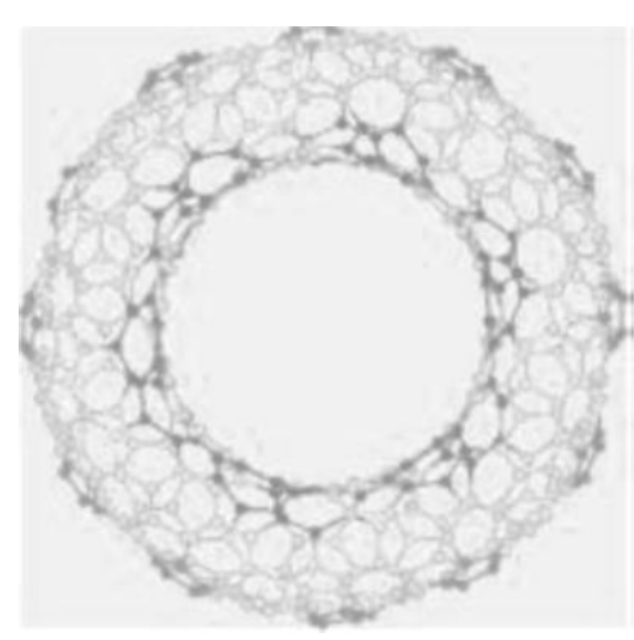

Figure 4: Nano Torus.

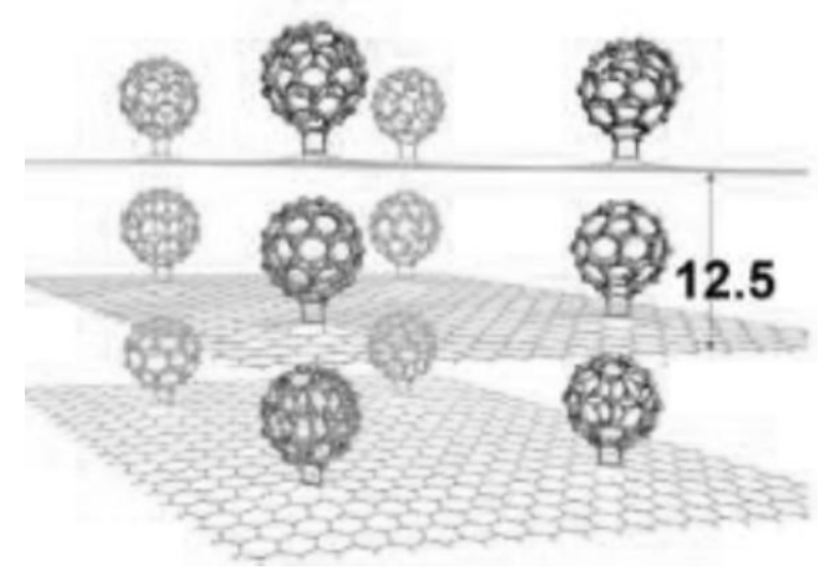

Figure 5: Nano Buds.

\section{Nanohorns}

They were first reported by Harris et al. and lijima et al. [1]. Single-walled carbon nanohorns (SWCNHs) are horn-shaped single-walled tubules with a conical tip.

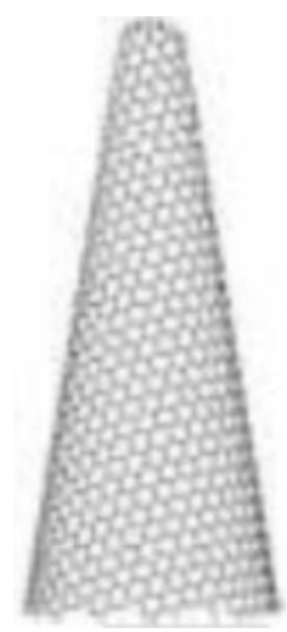

Figure 6: Nano Horns.
The primary advantage of SWNHs is that no catalyst is required for synthesis so high purity materials can be produced. Their high surface area and excellent electronic properties have led to promising results for their use as electrode material for energy storage [21]. Currently, SWCNHs have been widely studied for various applications, such as gas storage, adsorption, catalyst support, drug delivery system, magnetic resonance analysis, electrochemistry, biosensing application, photovoltaics and photoelectrochemical cells, photodynamic therapy, fuel cells, and so on [22].

\section{Micro and Nano Sensors in Biomedical Measurement}

Measurement science and technology continue to play vital roles in biomedical research and in routine healthcare. Over recent decades there has been a steady evolution of sensors for biomedical measurement aimed at clinical care in hospitals, fundamental biomedical research in the laboratory, or even self-care in the home [23]. The measurements of interest are diverse, ranging from pressure, force, flow and displacement to electrical field/charge, magnetic flux, and molecular species, such as gases, ions, proteins, bacteria, viruses, and DNA. The basic study of biological systems has included the detailed investigation of biological sensory mechanisms responsible for the senses of sight, hearing, taste, smell and touch [24]. There have been significant benefits to research in sensor science and technology from the inspiration that derives from these natural sensory systems [25], leading to a variety of activites in so-called biomimicry and biomimetics [26]. Sensor configurations must vary widely to meet the requirements of the measurement site, be it in a blood or tissue sample, or within living cells, tissues or organs. Thus the physical size of the sensor is important in all cases, either in order to reduce the sample volume needed or to minimize the influence that the mere presence of the sensor has on the biological environment in which it is situated. This is where advances in fabrication methods and technologies, such as MEMS and NEMS, play crucial roles and where recent developments have moved the state-of the art in terms of sensing phenomena firmly from the micro domain into the nano world. Conventional biological sensing generally relies on optical [27,28], electrochemical [29], and piezoelectric [30] technologies, some of which can achieve detection limits from nanomolar to femtomolar levels $[31,32]$. Although these methods are sensitive and reliable for molecular detection in vitro diagnostics, they suffer 
from disadvantages such as inherent complexity and requirement for multiple reagents and steps, signal amplification, relatively large sample size, and high cost. Nanomaterials possess unique properties that are amenable to biosensor applications because they are extremely sensitive to electronic perturbations $[33,34]$. One-dimesional nanowires, especially silicon nanowires, have shown promising biosensing performance [35-37] based on their electrical sensitivity to the analyte-induced surface charges. By using smaller nanotubes with all atoms on the surface, biosensors based on carbon nanotubes (CNTs) have been demonstrated for biomolecular sensing [38-40], and in particular, field effect transistors(FETs) based on semiconducting CNTs have been used as biosensors [41-45]. These CNT-based FET devices are extremely sensitive to variations in the surrounding environment because all the electrical current flows through the outermost layer of the CNT which is in direct contact with the analyte. Several groups have reported on the electrochemical detection of protein binding $[46,47]$ and DNA hybridization [48-51] using carbon nanotube field effect transistors(CNTFETs). The mechanism responsible for changing device characteristics is believed to be a charge - transfer reaction between analytes and CNTs, however, these approaches require complex multi-step and multi-reagent procedures to label CNTs with probe proteins or DNAs. In addition, treating the CNT surface, especially the area around the CNT-metal contact, could modify device characteristics [52], which may confound the sensing results. Recently, the enhancement of the DNA detection by incorporating $\mathrm{Au}$ nanoparticles into CNTFETs has been reported [53].

\section{Single-Walled Nanotubes (SWNT) Preparation and Characterization}

SWNTs prepared from laser ablation [54], HiPco [55] or related gas phase growth methods are typically contaminated with amorphous carbon and metal particles. The as-prepared material, in general, is purified by an oxidative treatment to remove amorphous carbon and an acid treatment to remove metal particles. Functionalization can be performed on the raw purified material as well as material individualized in aqueous surfactants (vide unfra). Covalently functionalized SWNTs are characterized by several analytical techniques. Absorption and resonance Raman spectroscopy are employed to ensure that the functionalization is covalent and occurs at the sidewalls, not at merely defect sites or at the ends of the SWNTs. Once covalent sidewall functionalization is confirmed, themogravimetric analysis (TGA) and x-ray photoelectron spectroscopy (XPS) are used to determine the degree of functionalization. Use of these techniques is difficult unless the modified carbon nanotubes are purified. Imaging techniques such as atomic force microscopy (AFM), scanning electron microscopy(SEM), and transmission electron microscopy (TEM) are used to analyze the diameter of the bundles or individuals, and AFM gives a good indication of average lengths of the nanotubes.

\section{Carbon Nanotube-Modified Composites}

Polymer-based composites and blends, where polymers serve as the matrices for inorganic, organic, or carbon fillers, have had enormous impact as engineering materials, and they are widely used in commercial products. Often carbon black, glass fibers, and phenolic resins are incorporated into the polymer hosts, resulting in significant improvements in mechanical properties, including impact strength and tensile and compressive moduli (stiffness) over that of the non-filled polymer. As stated previously, SWNTs exhibit extraordinary mechanical properties [56,57] such as tensile strengths of 50 to $200 \mathrm{GPa}$, estimated Young's moduli of 1 to $5 \mathrm{TPa}$, and high strains (ca. 5 to $6 \%$ ) at break [58]. Further, when released from strain, bent SWNTs recover their original form without direct fracture [59]. On the basis of these extraordinary mechanical properties and the large aspect ratio (typically $\approx 500$ to 1000 ) associated with individual tubes, SWNTs are excellent candidates of nanoreinforced polymer composite materials [60], complementing or substituting the traditional carbon black and glass fiber fillers. Morever, the functionalized SWNTs show further promise because their miscibility at $>1 \mathrm{wt} \%$ levels in the polymer host is often enhanced relative to the unfunctionalized SWNTs. Research on nanotube composites has concentrated, for the most part, on polymer-MWNT-based materials [61-64] wherein they exhibit mechanical properties that are superior to conventional polymer-based composites due to their considerably higher intrinsic strengths and moduli, and the fact that the stress transfer efficiency can be 10 times higher than that of traditional additives [55]. However, polymer-SWNT composites show even promise that the MWNT-based nanocomposites as potential high-performance engineering materials $[56,57]$. For instance, dynamic mechanical analysis (DMA) studies of in situ polymerized poly(methyl methacrylate)(PMMA)-SWNTs demonstrated that the tensile modulus increased by more than a factor of 2 
with only 0.1 wt\% SWNTs added [58]. These improvements are far in excess of that observed in the PMMA-MWNT nanocomposites. Indepentdent experiments on PMMA-SWNTs at low nanotube concentration $(<1 \mathrm{wt} \%)$ indicate that the polymer is intimately mixed with the nanotubes. Furthermore measurements of the melt rheology of polystyreneSWNT nanocomposites indicate a substantial increase in the viscosity and elasticity of the system at low shear rates, even at $1 \mathrm{wt} \%$ SWNT loadings. The lowfrequency linear oscillatory shear moduli for polystyrene functionalized-SWNT nanocomposites demonstrate a transition from liquid - like to solid - like behavior associated with the formation of a percolated network structure, while that for the unfunctionalized SWNT and polystyrene remains liquid - like for nanocomposites with $3 \mathrm{wt} \%$ SWNT. The formation of such a percolated nanoparticle network structure is a consequence of the dispersion of the functionalized SWNTs, the effective aspect ratio of the SWNTs, and, perhaps most importantly, the strength of polymerfunctionalized SWNT interaction. Thus, functionalization greatly increases the dispersion of SWNTs in polymer matrices, and the functional moiety increases the interfacial bonding or entanglement. This is in sharp contrast to unfunctionalized SWNTs, where dispersion and interfacial bonding or entanglement are minimal.

\section{Proteomic Analysis of Cellular Response Induced by Multi-Walled Carbon Nanotubes Exposure in A549 Cells}

$\mathrm{Li} \mathrm{Ju}$ et al. have been examined the wide application of multi-walled carbon nanotubes (MWCNT) on the serious concerns about their safety on human health and environment. However, the potential harmful effects of MWCNT remain unclear and contradictory. To clarify the potentially toxic effects of MWCNT and to elucidate the associated underlying mechanisms, the effects of MWCNT on human lung adenocarcinoma A549 cells were examined at both the cellular and the protein level. Cytotoxicity and genotoxicity were examined, followed by a proteomic analysis (2-DE coupled with LC-MS/MS) of the cellular response to MWCNT. The results of these research group demonstrate that MWCNT indicates cytotoxicity in A549 cells only at relatively high concentrations and longer exposure time. Within a relatively low dosage range $(30 \mathrm{mg} / \mathrm{ml})$ and short time period $(24 \mathrm{~h})$, MWCNT treatment does not induce significant cytotoxicity, cell cycle changes, apoptosis, or DNA damage. However, at these low doses and times, MWCNT treatment causes significant changes in protein expression. A total of 106 proteins show altered expression at various time points and dosages, and of these, 52 protein were further identified by MS. Identified proteins are involved in several cellular processes including proliferation, stress, and cellular skeleton organization. In particular, MWCNT treatment causes increase in actin expression. This increase has the potential to contribute to increased migration capacity and may be mediated by reactive oxygen species(ROS) [65].

\section{Carbon Nanotubes as Protein Carriers}

Sabrina F. Oliveira et al. have been reviewed Protein functionalized carbon nanomaterials for biomedical applications [66]. Several long-standing challenges in the delivery of biological materials such as proteins have been addressed via the scaffolding of these biomaterials to nanomaterials. Nanomaterials are of a similar size-scale as many biologicals, and are thereforewell-suited to their assisted delivery into organelles, cells, and tissues. Nanomaterials such as graphene, MWCNTs, and SWCNTs have a high surface area-to-mass ratio, which maximizes the scaffolding potential for biological cargoes. Significant progress has been made in the use of graphene, MWCNT, and SWCNT in cell studies. However, the majority of cases using CNP-protein conjugates for delivery have hinged on the use of SWCNT, which will be the focus of this section. As such, carbon nanomaterials such as SWCNTs have played a central role in developing delivery scaffolds for proteins, and could represent a promising platform for the development of molecular transporters.

\section{CNTs as Protein Transporters}

CNTs, in particular, have shown a largely ubiquitous ability to transport into a variety of organelles [67], cells [68], and tissues [69], likely due to their large aspect ratio and the ease with which they can be functionalized. A leading effort in the field has been put forth by the Dai group, who has developed multiple CNT-based protein delivery platforms. Using chemically oxidized SWCNT, the group has shown electrostatic scaffolding of proteins to SWCNT which are then internalized into cells via endocytosis [70]. These results show endosomal release of the SWCNTprotein conjugate into the cytoplasm, where a variety of protein-directed functions are observed. Subsequent work from the same group has explored the interaction of proteins using SWCNT as a scaffold with human cancer cells $\mathrm{CHO}$ and 3T3 [71]. Encouragingly, fluorescently labeled streptavidin alone does not enter 
cells, SWCNT-scaffolded streptavidin does via adsorption-mediated endocytosis. This study further revealed controlled apoptosis of mammalian cells via SWCNT mediated delivery of cytochrome c. These results are encouraging for SWCNT usage as a generic protein scaffolding and transportation tool for intracellular delivery.

\section{Uptake Mechanism of SWCNT-Protein Conjugates}

There exist several opinions on the mechanism by which SWCNT-protein conjugates are uptaken into cells. The two primary contending mechanisms are an energy-dependent endocytotic SWCNT-conjugate internalization mechanism, and an energy independent passive internalization mechanism. The vast amount of literature supporting either mechanism suggests that both are likely contributors to cellular SWCNT internalization [72]. A single mechanistic pathway applicable to all nanoparticle variants, cell lines and culture conditions is extremely unlikely. Rather, the diversity of methods used to functionalize SWCNT, and attach cargoes to SWCNT, determine the internalization mechanism in a manner that remains to be mapped in detail. Previous studies have shown that the functionalized SWCNT conjugate can either fully enable passive and irreversible internalization of nanoparticles into cellular organelles, or have no quantifiable permeability into cellular organelles, simply by tuning the functionalized SWCNT conjugate's zeta potential. Similar studies looking into SWCNT cellular internalization have observed "needle-like" penetration of the nanoparticle into cells [73]. Conversely, clathrinmediated endocytosis has been observed for proteinSWCNT conjugates [74]. While many of the studies showing energy-independent SWCNT internalization were performed with DNA- or polymercoated SWCNT, it is likely that the much larger size and complexity of protein-SWCNT conjugates necessitates an alternate and energy-dependent cellular internalization pathway. Kinetic studies of such pathways have been undertaken, sometimes suggesting an exocytosis contribution to the kinetics of protein-SWCNT conjugate intracellular transport [75]. Several groups have also undertaken detailed studies of how carbon nanotube size and surface modification can greatly affect the adsorption of proteins. For instance, Marchetti and co-workers found that human surfactant protein $D$, found in human respiratory secretions, adheres to varying extents on carbon nanotubes depending primarily on the nanotube functionalization with charged groups [76]. Because surfactant protein $D$ is central to the lung's inflammatory response, these findings are suggestive that nanotube functionalization can affect not only the delivery fate of proteinnanotube, but also the toxicity of the conjugate. Groups have also modeled the binding of proteins and peptides on SWCNT, based on the protein's hydrophilic: hydrophobic side chain ratio. For such modeling studies, endocytosis was also a preferred pathway for the update of protein- SWCNT conjugates. These studies investigated the molecular-scale details of how protein-SWCNT interactions modulate SWCNT proteincarrying capacity, and also toxicity [77].

\section{Toxicity of Delivered SWCNT-Protein Conjugates}

The use of SWCNT-protein conjugates for the delivery of biological cargoes relies on a thorough understanding of their toxicity. The increased use of SWCNT in therapeutic and biosensing applications has also spawned an interest in understanding the toxicity of these conjugates. Much like the internalization pathway of SWCNT conjugates was found to vary greatly depending on the conjugate's functionalization, the toxicity of said conjugates also varies depending on their functionalization [78]. Studies have shown through extensive analytical characterization, that SWCNT toxicity can be mediated by binding of blood serum proteins to the otherwise hydrophobic surface of SWCNT. Work by Ge and co-workers showed that the different binding capacities of blood proteins to SWCNT led to a competitive protein binding process mediated by each protein's adsorption capacity [79]. Proteins such as bovine fibrinogen, gamma globulin, transferrin, and bovine serum albumin were found to bind to SWCNT with adsorption rates that increase with the order in which these proteins are listed. Further analysis into the structure of these proteins showed that proteins with higher SWCNT adsorption rates also had more hydrophobic surface residues, suggesting that those proteins with more hydrophobic surface residues (Trp, Phe, Tyr) are likelier to bind to SWCNT [80]. In turn, SWCNT functionalized with different surface coverage of each blood protein mediated the cellular translocation pathways and cellular toxicity in human acute monocytic leukemia cells, and human umbilical vein endothelial cells [81]. Another study by Sacchetti and co-workers studied the adsorption of various blood plasma proteins onto SWCNT that had been pre-functionalized with varying quantities of PEG [82], along with Liu and coworkers [83]. Highly and sparsely PEGylated SWCNT were injected into mice, and proteomics analysis were then performed to determine the composition of the protein corona that had formed on the SWCNT surface. The study 
concluded that the pharmacokinetic profile of PEGylated SWCNT affected the competitive adsorption of blood proteins to the PEGylated SWCNT, which in turn shifted the fate of these complexes in living mice. Significant progress has been made in the elucidation of protein-SWCNT internalization mechanisms, from cells to model organisms. However, there is lack of, and need for, a systematic and predictable understanding of the parameters that determine protein-SWCNT fates in their interactions with biological systems. Advances in experimental and theoretical tools to study SWCNT biomolecule conjugate systems at the molecular scale [84] have emerged, but many remain to be extended for molecular scale SWCNT-protein studies. The risk of CNPs triggering an immune response should be also considered, since the protein components of the complement system can bind to carbon nanotubes. Certain studies have focused on how the functionalization of carbon nanoparticles, often with protein coronas, can attenuate or abate the immune response of nanoparticles in biological applications [85]. Such studies are particularly promising in suggesting that the fate, toxicity, lifetime, and therefore the utility of CNPs is highly tunable and can be engineered by the user via the nanoparticle corona. In the case of CNTs, the poly dispersity in CNT length has given rise to questions of how CNT length can affect CNT fate and toxicity in vivo. Asbestos-like pathogenicity has been observed for MWCNTs in the mesothelial lining of mouse body cavities, particularly for longer CNTs. This length-dependent toxicity has spurred further research into how to circumvent these length-dependent toxic effects. Studies show that proper functionalization of long CNTs can be used to alleviate the asbestos-like effects of long carbon nanotube species, which is again promising for a range of applications wishing to utilize the remarkable properties of carbon nanomaterials. Future studies to broaden our understanding of how to rationally design and predict protein coronas for SWCNT conjugates are needed to further the field of protein-SWCNT conjugates for sensing, bioengineering, and therapeutic applications.

\section{DNA Detection by Nanotubes}

Sebastian Kruss et al. have been reported the application of nanotubes for detecting of DNA [86]. The ability to detect changes in DNA sequence and structure may prove useful for applications in personalized medicine [87]. For example, single nucleotide polymorphisms (SNPs) are one of the most common types of genetic mutation, and can lead to a variety of autoimmune diseases [88], or the development of cancer $[89,90]$, among others. It has been demonstrated that DNA-wrapped SWCNTs can directly detect SNPs by examining hybridization kinetics between the SWCNT-bound sequence, and a complementary sequence in solution. Because of the nanoscale dimensions of the SWCNT sensors, this could enable the screening of high frequency singlenucleotide polymorphisms in a high throughput manner.

\section{DNA Hybridization}

Some early SWCNT-based optical sensors demonstrated the ability to detect DNA hybridization $[91,92]$. In this study, the exposure of single-stranded DNA-wrapped SWCNTs to a complementary 24-mer oligonucleotide resulted in a hypsochromic shift of 2 meV, allowing the detection of a complementary DNA strand down to concentrations of $6 \mathrm{nM}$. A model, based on the local dielectric environment, demonstrated that this shift could be attributed to an increased coverage of DNA on the SWCNT surface. The attribution of this shift to DNA hybridization was further validated by a FRET assay, in which a SWCNT-bound DNA strand and complement were conjugated with donor and acceptor fluorophores, respectively; upon addition of the complementary strand, a decrease in the donor emission was observed in conjunction with an increase in the acceptor emission. As may be expected, while hybridization kinetics of the free (non-SWCNT bound) DNA strands were very fast - occurring in less than 10 min - the kinetics of the SWCNT-bound DNA strand were considerably slower, reaching completion only after $13 \mathrm{~h}$ at $25{ }^{\circ} \mathrm{C}$. A detection limit of $6 \mathrm{nM}$ was observed, which is comparable with electrical microarray techniques [93], but higher than more recently techniques that utilize surface initiated enzymatic polymerization [94].

\section{Single Nucleotide Polymorphism (SNPs)}

Because the nanotube emission undergoes solvato chromic shifts upon DNA hybridization, it has been possible to utilize DNA-wrapped SWCNT as optical sensors for detecting single nucleotide polymorphisms [95]. In this study, SWCNT was suspended in a ssDNA sequence, and exposed to either a complementary DNA sequence, or a sequence containing a SNP. Using this system, the authors demonstrated the ability to detect a SNP in a complementary strand by comparing the wavelength shift, upon hybridization, of the SNP to that of the cDNA. Here, it was found that 
the final, equilibrium wavelength shifts were influenced by the presence of a SNP. In addition, while the equilibrium binding constants were the same for both complementary and SNP strands, the hybridization kinetics were faster for cDNA. As with previous hybridization studies, the kinetics of hybridization for SWCNT immobilized DNA were very slow, and in order to detect SNPs in this study, it was necessary to allow incubation times of up to $24 \mathrm{~h}$. Therefore, current SWCNT-based methods for the detection of SNPS are much slower than molecular beacon based approaches, in which incubation times of $30 \mathrm{~min}$ are sufficient [96]. It may be possible to decrease the incubation time required for SWCNT-based SNP sensors through further design of the SWCNT-DNA interface. Carbon nanotubes can quench organic fluorophores in solution [97]. This mechanism is distance dependent and can be used for biosensing applications. This principle is heavily used for graphene biosensors but there are several examples with carbon nanotubes as well. Yang et al. used this approach to detect complementary DNA sequences and proteins from solution. They prepared dye-labeled oligonucleotide sequences that could interact with complementary sequences or as aptamers with the protein thrombin. The dye-labeled DNA sequence was adsorbed onto the SWCNT-surface. If a complementary DNA-sequence was present in the sample competitive binding took place. The fluorescence of the dye was recovered because this binding event released the primary DNA sequence or at least changed its proximity to the quenching carbon nanotube species. This approach was used to detect oligonucleotide-sequences in solution with detection limits in the nanomolar range.

\section{Functionalization of Carbon Nanotubes for Biocompatibility and Biomolecular Recognition}

Recent years have witnessed a significant interest in biological applications of novel solid-state nanomaterials [99-104]. The unique physical properties of molecular- or nanoscale solids (dots or wires) when utilized in conjunction with the remarkable biomolecular recognition capabilities could lead to miniature biological electronics and optical devices including probes and sensors. Not only could these devices exhibit advantages over existing technology in size but also in performance. Several issues are important regarding nanomaterial/biosystems. One of them is biocompatibility, especially for in-vivo applications of implantable bioelectronics devices. Another is specificity that requires biofunctionalization of nanomaterials for recognition of only one type of target biomolecule in solution and rejection of others. Central to tackling these issues is surface functionalization of nanomaterials and elucidating the interfaces and interactions between nanomaterials and biosystems. Moonsub Shim et al. [98] have been showed that (1) nonspecific binding (NSB) of proteins to SWNTs, (2) functionalization of nanotubes for resisting nonspecific interactions, and (3) enabling specific binding of proteins to functionalized nanotubes. They find that streptavidin nonspecifically binds to as-grown SWNTs and show that prevention of NSB of streptavidin on SWNTs is achieved by coating nanotubes with a surfactant and poly(ethylene glycol), PEG. Selective binding of streptavidin is introduced by cofunctionalization of SWNTs with PEG and biotin. The results have implications to the nanotube biocompatibility issue and specificity of potential bioelectronic devices based on nanotubes. In an earlier communication, they have shown that protein binding to SWNTs is reliably enabled via a noncovalent sidewall functionalization scheme. In this manner, a variety of proteins have been successfully immobilized on SWNTs functionalized by 1-pyrenebutanoic acid succinimidyl ester. The pyrene moiety adsorbs onto the sidewalls of SWNTs via ठ-ठ interaction, and the succinimidyl ester group reacts with amine groups on lysine residues of proteins to form covalent amide linkages. Multiwalled carbon nanotubes have been functionalized with 4-hydroxynonenal (4-HNE) to induce adsorption of 4-HNE antibody. However, certain proteins are found to bind to SWNTs even without sidewall functionalization. A published example is the binding of a fullerene-specific monoclonal antibody to SWNTs. Such binding points to attractive interactions between certain proteins and as-grown SWNTs. It is interesting and important to address how to prevent NSB of proteins on SWNTs and at the same time introduce selective and specific binding.

\section{Protein Biosensors Based on Polymer Nanowires, Carbon Nanotubes}

The development of biosensors using electrochemical methods is a promising application in the field of biotechnology. High sensitivity sensors for the bio-detection of proteins have been developed using several kinds of nanomaterials. The performance of the sensors depends on the type of nanostructures with which the biomaterials interact. One dimensional (1-D) structures such as nanowires, nanotubes and nanorods are proven to have high potential for bioapplications. Anish Kumarthese et. el. have been 
reviewed three different kinds of nanostructures that have attracted much attention at recent times with their great performance as biosensors. Materials such as polymers, carbon and zinc oxide have been widely used for the fabrication of nanostructures because of their enhanced performance in terms of sensitivity, biocompatibility, and ease of preparation. Thus they consider polymer nanowires, carbon nanotubes and zinc oxide nanorods for discussion. They consider three stages in the development of biosensors: (a) fabrication of biomaterials into nanostructures, (b) alignment of the nanostructures and (c) immobilization of proteins. Two different methods by which the biosensors can be developed at each stage for all the three nanostructures are examined. Finally, they conclude by mentioning some of the major challenges faced by many researchers who seek to fabricate biosensors for real time applications [105].

\section{Clinical Applications of Biosensors Based on Field- Effect Transistors with Carbon Nanotubes or Nanowires}

Bodilovska has been described recent advances in the rapidly developing area of analyte detection using field-effect transistors (FETs) based on carbon nanotubes or nanowires. In this study behavior and advantages of one dimensional nanomaterials for biosensing application is depicted. Among one dimensional nanometer-scale materials, carbon nanotubes and nanowires offer unique electronic and mechanical properties that make them extremely attractive for the task of biosensing. The structures and work principles of FET biosensors based on carbon nanotubes/nanowires is discussed. Carbon nanotubes/silicon nanowire field-effect transistors have recently attracted great attention as promising tools in biosensor design because of their biocompatibility, size compatibility, ultra sensitivity, selectivity and label-free and real-time detection capabilities. In addition, interaction mechanisms between transducer elements of FET-biosensor (carbon nanotubes or nanowires) and target entities is also reviewed. Finally, applications of FET-type biosensors for measurement of different analytes is highlighted in this review. Proteins interaction, antibody-antigen reactions including prostate-specific antigen detection, DNA hybridization and enzymatic reactions involving glucose is shown [106].

\section{Nanotubes and Cancer}

Different kinds of carbon nanotubes (CNTs) have different properties. Multi-walled carbon nanotubes
(MWNTs) can bind with proteins, as various experimental techniques have revealed that covalent bonds formed between polymer radicals and acidtreated carbon nanotubes [107]. To achieve the attachment of nanotubes to proteins, two issues must be considered. The first is the state of dispersion of the CNT in the solution and the second is the interfacial adhesion between the CNT and the protein. Carbon nanotubes $[108,109]$ possess interesting property of adsorbing materials on their surface and heating up upon absorbing near-infrared light wave. In one study, it is shown that cancer cells tend to be coated with folate receptors, whereas normal cells are not. This is how carbon nanotubes target to cancer cells. When exposed to near-infrared light, carbon nanotubes quickly release excess energy as heat $\left(\sim 70^{\circ} \mathrm{C}\right)$, which can kill cancer cells. Kam et al. have shown that singlewalled carbon nanotubes are molecular transporters or carriers with very high optical absorbance in the 700$1100 \mathrm{~nm}$ near-infrared (NIR) light where biological systems are transparent In this special spectral window single-walled carbon nanotubes (SWNTs) have strong optical absorbance which is used for optical stimulation of nanotubes inside living cells. Continuous NIR radiation can cause cell death because of excessive local heating of SWNT in vitro. Selective cancer cell destruction can be achieved by functionalisation of SWNT with a folate moiety, selective internalisation of SWNTs inside cells labelled with folate receptor tumor markers, and NIR-triggered cell death, without harming receptor-free normal cells. Thus, the transporting capabilities of carbon nanotubes combined with suitable functionalisation chemistry and their intrinsic optical properties can lead to new classes of novel nanomaterials for drug delivery and cancer therapy.

\section{Carbon Nanotubes as Intracellular Protein Transporters}

Various proteins adsorb spontaneously on the sidewalls of acid-oxidized single-walled carbon nanotubes. This simple non-specific binding scheme can be used to afford noncovalent protein-nanotube conjugates. The proteins are found to be readily transported inside various mammalian cells with nanotubes acting as the transporter via the endocytosis pathway. Once released from the endosomes, the internalized protein nanotube conjugates can enter into the cytoplasm of cells and perform biological functions, evidenced by apoptosis induction by transported cytochrome c. Carbon nanotubes represent a new class of molecular transporters potentially useful for future in vitro and in-vivo protein delivery applications. 
Nadine Wong Shi Kam and Hongjie Dai reported a finding that SWNTs are generic intracellular transporters for various types of proteins $(\leq 80 \mathrm{kD})$ noncovalently and non-specifically bound (NSB) to nanotube sidewalls. The proteins investigated include streptavidin (SA), protein $A(S p A)$, bovine serum albumin (BSA) and cytochrome c (cyt-c). The intracellular protein transporting and uptake via nanotube carriers are also generic for various adherent and non-adherent mammalian cell lines including HeLa, NIH-3T3 fibroblast, HL60 and Jurkats cells. Energy dependent endocytosis is confirmed to be the internalization mechanism. Further, with cytochrome $c$ as the cargo protein, they present an exploration of the fate of internalized protein-SWNT-protein conjugates, attempts of releasing the conjugates from the endosome vesicles into the cell cytoplasm using chloroquine, and investigation of the biological functions of the released proteins. They observed apoptosis or programmed cell death induced by cyt-c transported inside cells by SWNTs after release from the endosomes. The results provide the first proof of concept of in vitro biological functionality and activity of proteins delivered by SWNT molecular transporters.

\section{Biological Imaging Using Carbon Nanotube Atomic Force Microscopy}

Aleksandr Noy et al. reported that carbon nanotube AFM tips can provide an increase in imaging resolution for several reasons. Obviously small end radii and high aspect ratio geometry contributes to the resolution improvement. Yet, the most important factor is that carbon nanotube has very small adhesive interaction with the sample. These small interactions forces translate into gentler and cleaner imaging. In addition, for a traditional geometry of the AFM tip the adhesion force contribute to an increase in contact area, thus degrading the resolution. Improvements that carbon nanotube AFM offers over the traditional AFM are obvious from a comparison of the test sample (sputtered $\mathrm{Nb}$ film) images. These images also demonstrate that CVD nanotube probes are superior to the mounted ones. They have images a number of non-pathogenic plant viruses using our technology. It is clear that use of a carbon nanotube AFM tip allowed us to observe virion substructure. Our observation agreed well with the existing structural model of the outer membrane of this virus showing pentameric and hexameric capsid arrangement. Notably, neither regular AFM probes nor mounted carbon nanotube probes are able to image isolated viruses on the surface with good resolution (mostly due to mechanical properties of virions). However, they were able to collect reasonable images of single isolated virions using probes produced by CVD techniques. In principle, this type of imaging may be useful for identification of single virions using a database of the virion surface structures [110].

\section{Complementary Detection of Prostate-Specific Antigen Using $\ln _{2} \mathrm{O}_{3}$ Nanowires and Carbon Nanotubes}

Nanostructured devices, fabricated using singlewalled carbon nanotubes [111] (SWNTs), silicon nanowires [112] (Si NWs), or metal oxide nanowires [114] (e.g., $\quad \ln _{2} \mathrm{O}_{3} \mathrm{NWs}$ ), are good candidates to manufacture future generations of biosensors. Nanotubes and nanowires have very high surface-tovolume ratios and, therefore, promise very high sensitivities. Recent biosensing literature has reported the use of either carbon nanotubes or nanowires as successful sensors for a number of biological analytes; however, combining these two nanomaterials may offer an interesting comparison and also novel sensing strategies. In addition, while several functionalization techniques have been developed to attach antibodies to SWNTs and Si NWs, little has been reported for biofunctionalization of metal oxide $\mathrm{NWs}$ (e.g., $\mathrm{In}_{2} \mathrm{O}_{3}$ and $\mathrm{SnO}_{2}$ ), which are traditionally the key materials for sensing. Li et al. reported complementary detection of prostate specific antigen (PSA) using n-type $\ln _{2} \mathrm{O}_{3}$ nanowires and p-type carbon nanotubes. PSA is an oncological marker for the presence of prostate cancer, which is the most frequently diagnosed cancer among men in the U.S. [115]. Despite its utmost importance, detection of PSA using NWs/SWNTs has not been reported. We have made two key innovations. First of all, a novel approach has been developed to covalently attach antibodies to $\ln _{2} \mathrm{O}_{3} \mathrm{NW}$ surfaces via the onsite surface synthesis of a succinimidyl linking molecule. Second, they have combined $\ln _{2} \mathrm{O}_{3} \mathrm{NWs}$ and SWNTs for the detection of PSA, which revealed complementary electrical response upon PSA binding. Furthermore, detection of PSA in solution has been demonstrated to be effective as low as $5 \mathrm{ng} / \mathrm{mL}$, a level useful for clinical diagnosis of prostate cancer.

\section{Toxicity Evaluation of Carbon Nanotubes in J774 Mouse Macrophages Utilizing a Proteomic Approach}

Dharani Das et al. studied the protein profiles of J774 cells after exposure to four well-characterized CNTs: single-walled and multi-walled (pristine and oxidized CNTs), at a dose range of $0-100 \mu \mathrm{g} / \mathrm{cm} 2$; and 
to examine the role of surface chemistry and metal impurities in CNTs-induced cellular toxicity.Shot-gun proteomic analyses were performed by MALDI-TOFTOF-MS. Data-mining using k-nearest neighbour clustering algorithm revealed an elevation in cellular endothelin-1, a pro-inflammatory and mitogenic peptide, and a decrease in cytoplasmic LDH levels, an indicator of cell membrane damage, notably in response to the oxidized CNTs. Elevation of o-tyrosine indicated formation of reactive oxygen species. Analysis of changes in the proteomic profiles of $\mathrm{J} 774$ cells revealed that mechanistic pathways relevant to key cellular functions were differentially impacted by the physicochemical properties of the CNT variants [116].

\section{Nanotubes Applications in the Proteins Extraction and Seperation}

As a first step to validate the use of carbon nanotubes as novel vaccine or drug delivery devices, their interaction with a part of the human immune system, complement, has been explored. Haemolytic assays were conducted to investigate the activation of the human serum complement system via the classical and alternative pathways. Western blot and sodium dodecyl sulphate-polyacrylamide gel electrophoresis (SDS-PAGE) techniques were used to elucidate the mechanism of activation of complement via the classical pathway, and to analyse the interaction of complement and other plasma proteins with carbon nanotubes. They report for the first time that carbon nanotubes activate human complement via both classical and alternative pathways. Carolina SalvadorMorales et al. conclude that complement activation by nanotubes is consistent with reported adjuvant effects, and might also in various circumstances promote damaging effects of excessive complement activation, such as inflammation and granuloma formation. C1q binds directly to carbon nanotubes. Protein binding to carbon nanotubes is highly selective, since out of the many different proteins in plasma, very few bind to the carbon nanotubes. Fibrinogen and apolipoproteins (AI, AIV and CIII) were the proteins that bound to carbon nanotubes in greatest quantity [117]. Chensong Pan et al. reported a method with carbon nanotubes functioning both as the adsorbent of solid-phase extraction (SPE) and the matrix for matrix assisted laser desorption/ionization mass spectrometry (MALDIMS) to analyze small molecules in solution has been developed. In this method, $10 \mu \mathrm{L}$ suspensions of carbon nanotubes in $50 \%(\mathrm{vol} / \mathrm{vol})$ methanol were added to the sample solution to extract analytes onto surface of carbon nanotubes because of their dramatic hydrophobicity. Carbon nanotubes in solution are deposited onto the bottom of tube with centrifugation. After removing the supernatant fluid, carbon nanotubes are suspended again with dispersant and pipetted directly onto the sample target of the MALDI-MS to perform a mass spectrometric analysis. It was demonstrated by analysis of a variety of small molecules that the resolution of peaks and the efficiency of desorption/ionization on the carbon nanotubes are better than those on the activated carbon. It is found that with the addition of glycerol and sucrose to the dispersant, the intensity, the ratio of signal to noise $(\mathrm{S} / \mathrm{N})$, and the resolution of peaks for analytes by mass spectrometry increased greatly. Compared with the previously reported method by depositing sample solution onto thin layer of carbon nanotubes, it is observed that the detection limit for analytes can be enhanced about 10 to 100 times due to solid-phase extraction of analytes in solution by carbon nanotubes. An acceptable result of simultaneously quantitative analysis of three analytes in solution has been achieved. The application in determining drugs spiked into urine has also been realized [118]. Vanesa Sanz et al. reported the use of carbon nanotubes as a gene delivery system has been extensively studied in recent years owing to its potential advantages over viral vectors. To achieve this goal, carbon nanotubes have to be functionalized to become compatible with aqueous media and to bind the genetic material. To establish the best conditions for plasmid DNA binding, they compare the dispersion properties of single-, double- and multi-walled carbon nanotubes (SWCNTs, DWCNTs and MWCNTs respectively) functionalized with a variety of surfactants by non-covalent attachment. The DNA binding properties of the functionalized carbon nanotubes were studied and compared by electrophoresis. Furthermore, a bilayer functionalization method for DNA binding on SWCNTs was developed that utilized RNA wrapping to solubilise the nanotubes and cationic polymers as a bridge between nanotubes and DNA [119]. Agata Spietelun et al. reviewed that solid phase microextraction find increasing applications in the sample preparation step before chromatographic determination of analytes in samples with a complex composition. These techniques allow for integrating several operations, such as sample collection, extraction, analyte enrichment above the detection limit of a given measuring instrument and the isolation of analytes from sample matrix. In this work the information about novel methodological and instrumental solutions in relation to different variants of 
solid phase extraction techniques, solid-phase microextraction (SPME), stir bar sorptive extraction (SBSE) and magnetic solid phase extraction (MSPE) is presented, including practical applications of these techniques and a critical discussion about their advantages and disadvantages. The proposed solutions fulfill the requirements resulting from the concept of sustainable development, and specifically from the implementation of green chemistry principles in analytical laboratories. Therefore, particular attention was paid to the description of possible uses of novel, selective stationary phases in extraction techniques, inter alia, polymeric ionic liquids, carbon nanotubes, and silica- and carbon-based sorbents. The methodological solutions, together with properly matched sampling devices for collecting analytes from samples with varying matrix composition, enable us to reduce the number of errors during the sample preparation prior to chromatographic analysis as well as to limit the negative impact of this analytical step on the natural environment and the health of laboratory employees [120].

\section{REFERENCES}

[1] lijima S. Helical Microtubules of Graphitic Carbon. Nature 1991; 354(6348): 56-58. https://doi.org/10.1038/354056a0

[2] Ouyang M, Huang JL, Lieber CM. One-dimensional energy dispersion of single-walled carbon nanotubes by resonant electron scattering. Phys Rev Lett 2002; 88(6): 066804. https://doi.org/10.1103/PhysRevLett.88.066804

[3] Zare K, Najafi F, Sadegh H. Studies of ab initio and Monte Carlo simulation on interaction of fluorouracil anticancer drug with carbon nanotube. J Nanostruc Chem 2013; 3(1): 1-8. https://doi.org/10.1186/2193-8865-3-71

[4] hostenson ET, Ren ZF, Chou TW. Advances in the science and technology of carbon nanotubes and their composites: a review. Compos Sci Technol 2001; 61(13): 1899-1912. https://doi.org/10.1016/S0266-3538(01)00094-X

[5] Troiani HE, Miki-Yoshida M, Camacho-Bragado GA, Marques MAL, Rubio A, Ascencio JA, Jose-Yacaman M. Direct observation of the mechanical properties of singlewalled carbon nanotubes and their junctions at the atomic level. Nano Lett 2003; 3(6): 751-755. https://doi.org/10.1021/nl0341640

[6] Wan XG, Dong JM, Xing DY. Optical properties of carbon nanotubes. Phys Rev B 1998; 58(11): 6756-6759. https://doi.org/10.1103/PhysRevB.58.6756

[7] Kostarelos K, Lacerda L, Pastorin G, Wu W, Wieckowski S, Luangsivilay J. A Bianco, Cellular uptake of functionalized carbon nanotubes is independent of functional group and cell type. Nat Nanotechnol 2007; 2(2): 108-113. https://doi.org/10.1038/nnano.2006.209

[8] Sadegh H, Shahryari-ghoshekandi R, Kazemi M. Study in synthesis and characterization of carbon nanotubes decorated by magnetic iron oxide nanoparticles. Int Nano Lett $2014 ; 4(4)$ : 129-135. https://doi.org/10.1007/s40089-014-0128-1

[9] Sadegh H, Shahryari-ghoshekandi R, Agarwal S, Tyagi I, Asif M, Gupta VK. Microwave-assisted removal of malachite green by carboxylate functionalized multi-walled carbon nanotubes: Kinetics and equilibrium study. J Mol Liq 2015; 206: $151-158$

https://doi.org/10.1016/j.molliq.2015.02.007

[10] Ando Y. Carbon nanotube: the inside story. J Nanosci Nanotechnol 2010; 10(6): 3726-3738. https://doi.org/10.1166/inn.2010.2017

[11] Cheng MMC, Cuda G, Bunimovich YL, Gaspari M, Heath JR, Hill HD, Mirkin A, Nijdam AJ, Terracciano R, Thundat T, Ferrari M, Nanotechnologies for biomolecular detection and medical diagnostics. Curr Opin Chem Biol 2011; 10: 11-19. https://doi.org/10.1016/j.cbpa.2006.01.006

[12] Hällström W, Mårtensson T, Prinz C, Gustavsson $P$, Montelius L, Samuelson L, Kanje M. Gallium phosphide nanowires as a substrate for cultured neurons. Nano Lett 2007; 7: 2960-2965. https://doi.org/10.1021/nl070728e

[13] Valentin N. Popov. Mat Sci and Engg R 2004; 43: 61. https://doi.org/10.1016/j.mser.2003.10.001

[14] Kroto HW, Heath JR, O'Brien SC, Curl RF, Smalley RE. C60: Buckminsterfullerene. Nature 1985; 318(14): 162-163. https://doi.org/10.1038/318162a0

[15] lijima S. Nature (London) 1991; 354: 56 https://doi.org/10.1038/354056a0

[16] Odom TW, Huang J-L, Kim P, Lieber CM. Atomic structure and electronic properties of single-walled carbon nanotubes. Nature 1998; 391: 62-64. https://doi.org/10.1038/34145

[17] Ganesh EN. Single Walled and Multi Walled Carbon Nanotube Structure, Synthesis and Applications. International Journal of Innovative Technology and Exploring Engineering (IJITEE) 2013; 2(4): ISSN: 2278-3075.

[18] Hirlekar R, Yamagar M, Garse H, Vij M, Kadam V. Carbon Nanotubes and Its Applications: A Review. Asian Journal of Pharmaceutical and Clinical Research 2009; 2(4).

[19] Shi Q, Yu Z, Liu Y, Gong H, Yin H, Zhang W, Liu J, Peng Y. Plasmonics properties of nano-torus: An FEM method. Optics Communications 2012; 285(21-22): 4542-4548. https://doi.org/10.1016/j.optcom.2012.06.032

[20] Wu X, Zeng XC. Periodic Graphene Nanobuds. Nano Lett 2008.

[21] Harris PJF, Tsang SC, Claridge JB, Green MLH. High resolution electron microscopy studied of a microporous carbon produced by arc evaporation. J Chem Soc Faraday Trans 1994; 90: 2799-802. https://doi.org/10.1039/ft9949002799

[22] Zhu S, Xu G. Single-walled carbon nanohorns and their applications. Nanoscale 2010; 2: 2538-2549. https://doi.org/10.1039/c0nr00387e

[23] Öberg PÅ, Togawa T, Spelman FA. Sensors in Medicine and Health Care. Wiley-VCH, Weinheim 2004.

[24] Courville J, Walsh J, Cordeau JP. Functional organization of the brain stem reticular formation and sensory input. Science 1962; 138: 973-5.

https://doi.org/10.1126/science.138.3544.973

[25] Rolfe P. Sensors and Systems that Mimic Nature. Eng Sci and Education J 1990; 6(4): 155-166. https://doi.org/10.1049/esej:19970403

[26] Müller R, Kuc R. Biosonar-inspired technology: goals, challenges and insights. Bioinspir Biomim 2007; 2(4): 146-61. https://doi.org/10.1088/1748-3182/2/4/S04

[27] Cooper MA. Optical biosensors in drug discovery. Nat Rev Drug Discov 2007; 1(7): 515-28. https://doi.org/10.1038/nrd838

[28] Voros J, Ramsden JJ, Csucs G, Szendro I, De Paul SM, Textor $\mathrm{M}$, et al. Optical grating coupler biosensors. Biomaterials 2002; 23(17): 3699-710. https://doi.org/10.1016/S0142-9612(02)00103-5

[29] Wang J. Electrochemical nucleic acid biosensors. Anal Chim 
Acta 2002; 469(1): 63-71

https://doi.org/10.1016/S0003-2670(01)01399-X

[30] Janshoff A, Galla HJ, Steinem C. Piezoelectric mass-sensing devices as biosensors - an alternative to optical biosensors? Angew Chem Int Ed 2000; 39(22): 4004-32.

https://doi.org/10.1002/1521-

3773(20001117)39:22<4004::AID-ANIE4004>3.0.CO;2-2

[31] Li T, Liu DJ, Wang ZX. Microarray-based Raman spectroscopic assay for kinase inhibition by gold nanoparticle probes. Biosens Bioelectron 2002; 24(11): 3335-9.

https://doi.org/10.1016/..bios.2009.04.033

[32] Hucknall A, Kim DH, Rangarajan S, Hill RT, Reichert WM, Chilkoti A. Simple fabrication of antibody microarrays on nonfouling polymer brushes with femtomolar sensitivity for protein analytes in serum and blood. Adv Mater 2009; 21(19): 1968-71.

https://doi.org/10.1002/adma.200803125

[33] Lei CX, Hu SQ, Gao N, Shen GL, Yu RQ. An amperometric hydrogen peroxide biosensor based on immobilizing horseradish peroxidase to a nano-Au monolayer supported by sol-gel derived carbon ceramic electrode. Bioelectrochemistry 2004; 65(1): 33-9.

https://doi.org/10.1016/j.bioelechem.2004.06.002

[34] Liu ZM, Yang Y, Wang H, Liu YL, Shen GL, Yu RQ. A hydrogen peroxide biosensor based on nano-Au/PAMAM dendrimer/cystamine modified gold electrode. Sens Actuators B: Chem 2005; 106(1): 394-400. https://doi.org/10.1016/j.snb.2004.08.023

[35] Cui Y, Wei QQ, Park HK, Lieber CM. Nanowire nanosensors for highly sensitive and selective detection of biological and chemical species. Science 2001; 293(5533): 1289-92. https://doi.org/10.1126/science.1062711

[36] Hahm J, Lieber CM. Direct ultrasensitive electrical detection of DNA and DNA sequence variations using nanowire nanosensors. Nano Lett 2004; 4(1): 51-4. https://doi.org/10.1021/nl034853b

[37] Li Z, Chen Y, Li X, Kamins TI, Nauka K, Williams RS. Sequence-specific label-free DNA sensors based on silicon nanowires. Nano Lett 2004; 4(2): 245-7. https://doi.org/10.1021/n1034958e

[38] Chen RJ, Bangsaruntip S, Drouvalakis KA, Kam NWS, Shim $\mathrm{M}$, Li YM, et al. Noncovalent functionalization of carbon nanotubes for highly specific electronic biosensors. Proc Natl Acad Sci USA 2003; 100(9): 4984-9. https://doi.org/10.1073/pnas.0837064100

[39] Li J, Ng HT, Cassell A, Fan W, Chen H, Ye Q, et al. Carbon nanotube nanoelectrode array for ultrasensitive DNA detection. Nano Lett 2003; 3(5): 597-602. https://doi.org/10.1021/nl0340677

[40] Wang J. Carbon-nanotube based electrochemical biosensors: a review. Electroanalysis 2005; 17(1): 7-14. https://doi.org/10.1002/elan.200403113

[41] Abe M, Murata K, Kojima A, Ifuku Y, Shimizu M, Ataka T, et al. Quantitative detection of protein using a top-gate carbon nanotube field effect transistor. J Phys Chem C 2007; 111(24): 8667-70. https://doi.org/10.1021/jp071420e

[42] Allen BL, Kichambare PD, Star A. Carbon nanotube field effect- transistor-based biosensors. Adv Mater 2007; 19(11): 1439-51.

https://doi.org/10.1002/adma.200602043

[43] Avouris P. Molecular electronics with carbon nanotubes. Acc Chem Res 2002; 35(12): 1026-34. https://doi.org/10.1021/ar010152e

[44] Kim JP, Lee BY, Hong S, Sim SJ. Ultrasensitive carbon nanotube-based biosensors using antibody-binding fragments. Anal Biochem 2008; 381(2): 193-8.

https://doi.org/10.1016/j.ab.2008.06.040

[45] Kim JP, Lee BY, Lee J, Hong S, Sim SJ. Enhancement of sensitivity and specificity by surface modification of carbon nanotubes in diagnosis of prostate cancer based on carbon nanotube field effect transistors. Biosens Bioelectron 2009; 24(11): 3372-8.

https://doi.org/10.1016/j.bios.2009.04.048

[46] Li C, Curreli M, Lin H, Lei B, Ishikawa FN, Datar R, et al. Complementary detection of prostate-specific antigen using $\ln (2) \mathrm{O}(3)$ nanowires and carbon nanotubes. J Am Chem Soc 2005; 127(36): 12484-5. https://doi.org/10.1021/ja053761g

[47] Star A, Gabriel JCP, Bradley K, Gruner G. Electronic detection of specific protein binding using nanotube FET devices. Nano Lett 2003; 3(4): 459-63. https://doi.org/10.1021/nl0340172

[48] Martinez MT, Tseng YC, Ormategui N, Loinaz I, Eritja R, Bokor J. Label-free DNA biosensors based on functionalized carbon nanotube field effect transistors. Nano Lett 2009; 9(2): 530-6. https://doi.org/10.1021/nl8025604

[49] Dong XC, Lau CM, Lohani A, Mhaisalkar SG, Kasim J, Shen $Z X$, et al. Electrical detection of femtomolar DNA via goldnanoparticle enhancement in carbon-nanotube network fieldeffect transistors. Adv Mater 2008; 20(12): 2389-93. https://doi.org/10.1002/adma.200702798

[50] Star A, Tu E, Niemann J, Gabriel JCP, Joiner CS, Valcke C. Labelfree detection of DNA hybridization using carbon nanotube network field-effect transistors. Proc Natl Acad Sci USA 2006; 103(4): 921-6. https://doi.org/10.1073/pnas.0504146103

[51] Gui EL, Li LJ, Lee PS, Lohani A, Mhaisalkar SG, Cao Q, et al. Electrical detection of hybridization and threading intercalation of deoxyribonucleic acid using carbon nanotube network field-effect transistors. Appl Phys Lett 2006; 89(23): 232104-6 https://doi.org/10.1063/1.2399355

[52] Chen ZH, Appenzeller J, Knoch J, Lin YM, Avouris P. The role of metal-nanotube contact in the performance of carbon nanotube field-effect transistors. Nano Lett 2005; 5(7): 1497502.

https://doi.org/10.1021/nl0508624

[53] Zhang J, Song SP, Zhang LY, Wang LH, Wu HP, Pan D, et al. Sequence-specific detection of femtomolar DNA via a chronocoulometric DNA sensor (CDS): effects of nanoparticle-mediated amplification and nanoscale control of DNA assembly at electrodes. J Am Chem Soc 2006; 128(26): 8575-80.

https://doi.org/10.1021/ja061521a

[54] Hennrich F, et al. Preparation, characterization, and applications of free-standing single walled carbon nanotube thin films. Phys Chem Chem Phys 2002; 4: 2273. https://doi.org/10.1039/b201570f

[55] Chiang IW, et al. Purification and characterization of singlewall carbon nanotubes (SWNTs) obtained from the gasphase decomposition of $\mathrm{CO}$ (HiPco process). J Phys Chem B 2001; 105: 8297. https://doi.org/10.1021/jp0114891

[56] Yakobson BI, Brabec CJ, Bernholc J. Nanomechanics of carbon tubes: instabilities beyond linear response. Phys Rev Lett 1996; 76: 2511.

https://doi.org/10.1103/PhysRevLett.76.2511

[57] Walters DA, et al. Elastic strain of freely suspended singlewall carbon nanotube ropes. Appl Phys Lett 1999; 74: 3803. https://doi.org/10.1063/1.124185

[58] Yu MF, et al. Tensile loading of ropes of single wall carbon nanotubes and their mechanical properties. Phys Rev Lett 2000; 84: 5552.

https://doi.org/10.1103/PhysRevLett.84.5552

[59] Cooper CA, Young RJ, Halsall M. Investigation into the deformation of carbon nanotubes and their composites through the use of Raman spectroscopy. Composites A Appl Sci Mfg 2001; 32: 401. 


\section{https://doi.org/10.1016/S1359-835X(00)00107-X}

[60] Barraza HJ, et al. SWNT-filled thermoplastic and elastomeric composites prepared by miniemulsion polymerization. Nano Lett 2002; 2: 797. https://doi.org/10.1021/n10256208

[61] Qian D, et al. Load transfer and deformation mechanisms in carbon nanotube- polystyrene composites. Appl Phys Lett 2000; 76: 2868.

https://doi.org/10.1063/1.126500

[62] Wagner HD, et al. Stress-induced fragmentation of multiwall carbon nanotubes in a polymer matrix. Appl Phys Lett 1998; 72: 188.

https://doi.org/10.1063/1.120680

[63] Schadler LS, Giannaris SC, Ajayan PM. Load transfer in carbon nanotube epoxy composites. Appl Phys Lett 1998; 73: 3842. https://doi.org/10.1063/1.122911

[64] Cooper CA, Young RJ. Investigation of structure/property relationships in particulate composites through the use of Raman spectroscopy. J Raman Spectrosc 1999; 30: 929. https://doi.org/10.1002/(SICl)10974555(199910)30:10<929::AID-JRS462>3.0.CO;2-7

[65] Ju L, Zhang G, Zhang X, et al. Proteomic Analysis of Cellular Response Induced by Multi-Walled Carbon Nanotubes Exposure in A549 Cells. PLOS ONE 2004; 9(1): 1-15.

[66] Sabrina F, Oliveira A, Bisker G, Naveed A, et al. Protein functionalized carbon nanomaterials for biomedical applications. Carbon 2015; 95: 767-779. https://doi.org/10.1016/j.carbon.2015.08.076

[67] Giraldo JP, et al. Plant nanobionics approach to augment photosynthesis and biochemical sensing. Nat Mater 2014; 13(4): 400e408.

[68] Vashist SK, et al. Delivery of drugs and biomolecules using carbon nanotubes. Carbon 2011; 49(13): 4077e4097.

[69] Giraldo JP, et al. A Ratiometric sensor using single chirality near-infrared fluorescent carbon nanotubes: application to in vivo monitoring. Small 2015; 11(32): 3973e3984.

[70] Kam NWS, Dai HJ. Carbon nanotubes as intracellular protein transporters: generality and biological functionality. J Am Chem Soc 2005; 127(16): 6021e6026.

[71] Kam NWS, et al. Nanotube molecular transporters: Internalization of carbon nanotube-protein conjugates into mammalian cells. J Am Chem Soc 2004; 126(22): $6850 \mathrm{e} 6851$.

[72] Vardharajula $S$, et al. Functionalized carbon nanotubes: biomedical applications. Int J Nanomedicine 2012; 7: 5361 e5374.

[73] Cheung W, et al. DNA and carbon nanotubes as medicine. Adv Drug Deliv Rev 2010; 62(6): 633e649.

[74] Kam NWS, Liu ZA, Dai HJ. Carbon nanotubes as intracellular transporters for proteins and DNA: an investigation of the uptake mechanism and pathway. Angew Chemie Int Ed 2006; 45(4): 577e581.

[75] Holt BD, Dahl KN, Islam MF. Cells take up and recover from protein stabilized single-wall carbon nanotubes with two distinct rates. ACS Nano 2012; 6(4): 3481e3490.

[76] Marchetti $M$, et al., Adsorption of surfactant protein $D$ from human respiratory secretions by carbon nanotubes and polystyrene nanoparticles depends on nanomaterial surface modification and size. Philos Trans R Soc Lond B Biol Sci 2015; 370(1661): 20140038.

https://doi.org/10.1098/rstb.2014.0038

[77] Sanz V, et al. Modeling the binding of peptides on carbon nanotubes and their use as protein and DNA carriers. J. Nanoparticle Res 2012; 14(2). https://doi.org/10.1007/s11051-011-0695-2

[78] Dumortier $\mathrm{H}$, et al. Functionalized carbon nanotubes are noncytotoxic and preserve the functionality of primary immune cells. Nano Lett 2006; 6: 1522, 2006; 6(12): 3003e3003.
[79] Ge CC, et al. Binding of blood proteins to carbon nanotubes reduces cytotoxicity. Proc Natl Acad Sci USA 2011; 108(41): $16968 \mathrm{e} 16973$.

[80] Sacchetti C, et al. Surface polyethylene glycol conformation influences the protein corona of polyethylene glycol-modified single-walled carbon nanotubes: potential implications on biological performance. ACS Nano 2013; 7(3): 1974e1989.

[81] Liu Z, et al. In vivo bio distribution and highly efficient tumor targeting of carbon nanotubes in mice. Nat Nanotechnol 2007; 2(1): 47e52.

[82] Johnson RR, Johnson ATC, Klein ML. Probing the structure of DNA- carbon nanotube hybrids with molecular dynamics. Nano Lett 2008; 8(1): 69e75.

[83] Marchesan S, et al. The winding road for carbon nanotubes in nanomedicine. Mater Today 2015; 18(1). https://doi.org/10.1016/j.mattod.2014.07.009

[84] Poland CA, et al. Carbon nanotubes introduced into the abdominal cavity of mice show asbestos-like pathogenicity in a pilot study. Nat Nanotechnol 2008; 3(7): 423e428.

[85] Ali-Boucetta $\mathrm{H}$, et al., Asbestos-like Pathogenicity of Long Carbon anotubes Alleviated by Chemical Functionalization. Angew Chemie Int Ed 2013; 52(8): 2274e2278.

[86] Kruss S, Andrew J, et al. Carbon nanotubes as optical biomedical sensors. Advanced Drug Delivery Reviews 2013; $1-18$. https://doi.org/10.1016/j.addr.2013.07.015

[87] Liu SJ. Epigenetics advancing personalized nanomedicine in cancer therapy. Adv Drug Deliver Rev 2012; 64(13): 15321543. https://doi.org/10.1016/j.addr.2012.08.004

[88] Schork NJ, Fallin D, Lanchbury JS. Single nucleotide polymorphisms and the future of genetic epidemiology. Clin Genet 2000; 58(4): 250-264. https://doi.org/10.1034/j.1399-0004.2000.580402.x

[89] Wang DG, Fan JB, Siao CJ, Berno A, Young P, Sapolsky R, et al. Large-scale identification, mapping, and genotyping of single-nucleotide polymorphisms in the human genome. Science 1998; 280(5366): 1077-1082. https://doi.org/10.1126/science.280.5366.1077

[90] Wang VO, Peterson JL, Shi M, Spiegel J, Sung LM, Witonsky $\mathrm{J}$, Zacharia LF, Kennedy K, Jamieson R, Stewart J, Consortium IH. A haplotype map of the human genome. Nature 2005; 437(7063): 1299-1320. https://doi.org/10.1038/nature04226

[91] Jeng ES, Moll AE, Roy AC, Gastala JB, Strano MS. Detection of DNA hybridization using the near-infrared bandgap fluorescence of single-walled carbon nanotubes. Nano Lett 2006; 6(3): 371-375. https://doi.org/10.1021/nl051829k

[92] Jeng ES, Barone PW, Nelson JD, Strano MS. Hybridization kinetics and thermodynamics of DNA adsorbed to individually dispersed single-walled carbon nanotubes. Small 2007; 3(9): 1602-1609. https://doi.org/10.1002/smll.200700141

[93] Dharuman V, Nebling E, Grunwald T, Albers J, Blohm L, Elsholz B, Worl R, Hintsche R. DNA hybridization detection on electrical microarrays using coulostatic pulse technique; Biosens Bioelectron 2006; 22(5): 744-751. https://doi.org/10.1016/j.bios.2006.02.014

[94] Tjong $\mathrm{V}, \mathrm{Yu} \mathrm{H}$, Hucknall A, Rangarajan S, Chilkoti A. Amplified on-chip fluorescence detection of DNA hybridization by surface-initiated enzymatic polymerization Anal Chem 2011; 83(13): 5153-5159. https://doi.org/10.1021/ac200946t

[95] Jeng ES, Nelson JD, Prather KLJ, Strano MS. Detection of a single nucleotide polymorphism using single-walled carbonnanotube near-infrared fluorescence. Small 2010; 6(1): 4043.

https://doi.org/10.1002/smll.200900944 
[96] Lin YW, Ho HT, Huang CC, Chang HT. Fluorescence detection of single nucleotide polymorphisms using a universalmolecular beacon. Nucleic Acids Res 2008; 36(19): e123.

https://doi.org/10.1093/nar/gkn537

[97] Zhu Z, Yang R, You M, Zhang X, Wu Y, Tan W. Singlewalled carbon nanotube as an effective quencher. Anal Bioanal Chem 2010; 396(1): 73-83. https://doi.org/10.1007/s00216-009-3192-z

[98] Shim M, Wong N, Shi K, Chen RJ, et al. Functionalization of Carbon Nanotubes for Biocompatibility and Biomolecular Recognition 2002; 2(4): 285-288.

[99] Bruchez M, Moronne M, Gin P, Weiss S, Alivisatos AP. Science 1998; 281: 2013-2016 https://doi.org/10.1126/science.281.5385.2013

[100] Chan W, Nie S. Science 1998; 281: 2016-2018. https://doi.org/10.1126/science.281.5385.2016

[101] Taton T, Mirkin C, Letsinger R. Science 2000; 289: 17571760. https://doi.org/10.1126/science.289.5485.1757

[102] Cui Y, Wei Q, Park H, Lieber C. Science 2001; 293: 12891292. https://doi.org/10.1126/science.1062711

[103] Chen R, Zhang Y, Wang D, Dai H. J Am Chem Soc 2001; 123: 123.

[104] Erlanger BF, Chen B, Zhu M, Brus LE. Nano Lett 2001; 1: 465 . https://doi.org/10.1021/n1015570r

[105] Kumar AM, Jung S, Ji T. Protein Biosensors Based on Polymer Nanowires, Carbon Nanotubes and Zinc Oxide Nanorods. Sensors 2011; 11: 5087-5111. https://doi.org/10.3390/s110505087

[106] Bodilovska DS. Clinical Applications of Biosensors Based on Field-Effect Transistors with Carbon Nanotubes or Nanowires. Биомедицинские приборы и системы 2013; 2: 53-58.

[107] Chen RJ, Zhang Y, Wang D, Dai H. Noncovalent sidewall functionalization of single-walled carbon nanotubes for protein immobilization. J Am Chem Soc 2001; 123: 38383839.

https://doi.org/10.1021/ja010172b

[108] Kam NWS, O'Connell M, Wisdom JA, Dai H. Carbon nanotubes as multifunctional biological transporters and near-infrared agents for selective cancer cell destruction. PNAS 2001; 102: 11600-11605. https://doi.org/10.1073/pnas.0502680102

[109] Teker K, Sivakumar K, Wickstrom E, Panchapakesan B. 'Functionalization of carbon nanotubes with antibodies for breast cancer detection applications', Proceed. Int'l. Conf. on
MEMS, NANO, and Smart Systems, 2001; pp. 48-53.

[110] Noy A, De Yoreo JJ, Malkin AJ. Carbon Nanotube Atomic Force Microscopy for Proteomics and Biological Forensics 2002.

[111] Chen RJ, Bangsaruntip S, Drouvalakis KA, Shi Kam NW, Shim M, Li Y, Kim W, Utz PJ, Dai H. Proc Natl Acad Sci USA 2003; 100: 4984.

https://doi.org/10.1073/pnas.0837064100

[112] (a) Patolsky F, Lieber CM. Mater Today 2004; 8: 20. https://doi.org/10.1016/S1369-7021(05)00791-1

(b) Bunimovich YL, Ge G, Beverly KC, Ries RS, Hood L, Heath JR. Langmuir 2004; 20: 10630. https://doi.org/10.1021/la047913h

[113] Li C, Curreli M, Lin H, Lei B. Complementary Detection of Prostate- specific Antigen Using $\ln _{2} \mathrm{O}_{3}$ Nanowires and Carbon Nanotubes. J Am Chem Soc 2005; 127: 1248412485 https://doi.org/10.1021/ja053761g

[114] Curreli M, Li C, Sun, Lei B, Gundersen MA, Thompson ME, Zhou CJ. Am Chem Soc 2005; 127: 6922. https://doi.org/10.1021/ja0503478

[115] Li X, Zhang YP, Kim HS, Bae KH, Stantz KM, Lee SJ, Jung C, Jimenez JA, Gardner TA, Jeng MH, Kao C. Cancer Res 2005; 65: 1941 https://doi.org/10.1158/0008-5472.CAN-04-3666

[116] Dharani D, Breznan D, Vincent R, Kumarathasan P. Toxicity evaluation of carbon nanotubes in $\mathrm{J} 774$ mouse macrophages utilizing a proteomic approach. J Proteomics Bioinform 2014; 7(8): 81-90

[117] Salvador-Morales C, Flahaut E, Sim E, Sloan J, Green MLH Sim RB. Complement activation and protein adsorption by carbon nanotubes. Molecular Immunology 2006; 43: 193201. https://doi.org/10.1016/j.molimm.2005.02.006

[118] Pan C, Xu S, Zou H, Guo Z, Zhang Y, Guo B. Carbon Nanotubes as Adsorbent of Solid-Phase Extraction and Matrix for Laser Desorption/Ionization Mass Spectrometry. J Am Soc Mass Spectrom 2005; 16: 263-270. https://doi.org/10.1016/j.jasms.2004.11.005

[119] Sanz V, Borowiak E, Lukanov P, Marie Galibert A, Flahaut E Coley HM, Ravi S, Silva P, McFadden J. Optimising DNA binding to carbon nanotubes by non-covalent methods. Original text.

[120] Spieteluna A, Marcinkowskia $\measuredangle$, de la Guardiab $M$, Namie'snik J. Recent developments and future trends in solid phase microextraction techniques towards green analytical chemistry. Journal of Chromatography A 2013; 1321: $1-13$ https://doi.org/10.1016/j.chroma.2013.10.030 